\title{
In Vivo and In Vitro Characterization of a Novel MAO-B Inhibitor Radioligand, ${ }^{18}$ F-Labeled Deuterated Fluorodeprenyl
}

\author{
Sangram Nag ${ }^{1}$, Patrik Fazio ${ }^{1}$, Lutz Lehmann², Georg Kettschau ${ }^{2}$, Tobias Heinrich ${ }^{2}$, Andrea Thiele ${ }^{2}$, Marie Svedberg ${ }^{1}$, \\ Nahid Amini ${ }^{1}$, Samira Leesch ${ }^{3}$, Ana M. Catafau ${ }^{3}$, Jonas Hannestad ${ }^{4}$, Andrea Varrone ${ }^{1}$, and Christer Halldin ${ }^{1}$ \\ ${ }^{1}$ Centre for Psychiatric Research, Department of Clinical Neuroscience, Karolinska Institutet, Stockholm, Sweden; ${ }^{2}$ Bayer \\ HealthCare AG, Global Drug Discovery, Berlin, Germany; ${ }^{3}$ Piramal Imaging GmbH, Berlin, Germany; and ${ }^{4} U C B$ Pharma, \\ Braine-l'Alleud, Belgium
}

\begin{abstract}
The aim of this study was to radiolabel a novel bis-deuterium substituted L-deprenyl analog (fluorodeprenyl- $\mathrm{D}_{2}$ ) with ${ }^{18} \mathrm{~F}$ and to evaluate its potential to visualize and quantify monoamine oxidase (MAO) B activity in vivo. Methods: The precursor compound $(5 a+$ 5b) and reference standard (6) were synthesized in multistep syntheses. Recombinant human MAO-B and MAO-A enzyme preparations were used to determine inhibitory concentrations of $50 \%$. Radiolabeling was accomplished by a nucleophilic substitution reaction. Whole-hemisphere autoradiography was performed with ${ }^{18} \mathrm{~F}$-fluorodeprenyl- $\mathrm{D}_{2}$. A PET study was performed on a cynomolgus monkey. Radiometabolites were measured in monkey plasma using high-performance liquid chromatography. Results: The $50 \%$ inhibitory concentration of compound 6 for MAO-B was $227 \pm 36.8 \mathrm{nM}$. Radiolabeling was accomplished with high radiochemical yield, purity, and specific radioactivity. The autoradiography binding density of ${ }^{18} \mathrm{~F}$-fluorodeprenyl- $\mathrm{D}_{2}$ was consistent with known MAO-B expression in the human brain. In vivo, ${ }^{18} \mathrm{~F}$-fluorodeprenyl- $\mathrm{D}_{2}$ showed favorable kinetic properties, with relatively fast washout from the brain. Regional time-activity curves were better described by the 2-tissuecompartment model. Administration of a $1 \mathrm{mg} / \mathrm{kg}$ dose of L-deprenyl yielded $70 \%$ inhibition of MAO-B in all regions. Radiometabolite studies demonstrated $20 \%$ unchanged radioligand at $120 \mathrm{~min}$ after injection. ${ }^{18} \mathrm{~F}$-fluorodeprenyl- $\mathrm{D}_{2}$ showed less irreversibility than did previously reported MAO-B radioligands. Conclusion: The results suggest that ${ }^{18} \mathrm{~F}$-fluorodeprenyl- $\mathrm{D}_{2}$ is a suitable PET radioligand for visualization of MAO-B activity in the human brain.
\end{abstract}

Key Words: ${ }^{18}$ F-fluorodeprenyl- $\mathrm{D}_{2}$; monoamine oxidase; monkey; PET

J Nucl Med 2016; 57:315-320

DOI: 10.2967/jnumed.115.161083

$\mathbf{M}$ onoamine oxidase (MAO) plays an important role in regulating chemical neurotransmitters by catalyzing oxidative deamination of, for example, monoamine neurotransmitters (1). MAO is an important therapeutic target for neurologic disorders such as Alzheimer disease

Received May 19, 2015; revision accepted Oct. 19, 2015.

For correspondence or reprints contact: Sangram Nag, Department of Clinical Neuroscience, Karolinska Hospital, Karolinska Institutet, S-17176, Stockholm, Sweden.

E-mail: sangram.nag@ki.se

Published online Nov. 19, 2015.

COPYRIGHT (c) 2016 by the Society of Nuclear Medicine and Molecular Imaging, Inc.
(2), Parkinson disease (3), and depression (4). According to biochemical and pharmacologic properties, this enzyme exists in A and B isoforms (5). In the human brain, MAO-B is the predominant isoform and constitutes up to about $70 \%$ of total brain MAO activity (6). MAO-B selectively oxidizes monoamines such as $O$-tyramine, phenethylamine, and tele- $N$-methyl histamine and generates hydrogen peroxide, which can react to form highly reactive oxygen species (7). Previously reported increased levels of MAO-B level in Alzheimer disease patients might be associated with a progressive increase in oxidative stress $(8)$ and a consequent reactive astrogliosis $(9,10)$. Because astrocyte activity and, consequently, the activity of the MAO-B system is upregulated in neuroinflammatory processes, radiolabeled MAO-B inhibitors may serve as an imaging biomarker in neuroinflammation and neurodegeneration, including Alzheimer disease (11).

PET, a high-resolution, sensitive, and noninvasive molecular imaging technique, has been successfully used in visualizing the localization of MAO-B activity for studying neurodegenerative diseases (12). Several PET radioligands have been developed to study MAO-B activity, such as ${ }^{11} \mathrm{C}$-pargyline (13), ${ }^{11} \mathrm{C}$-deprenyl (12), ${ }^{11} \mathrm{C}$-deprenyl- $\mathrm{D}_{2}(2)$, ${ }^{11} \mathrm{C}-\mathrm{SL} 25.1188$ (14), ${ }^{11} \mathrm{C}-\mathrm{MD} 230254$ (15), DL-4- ${ }^{18} \mathrm{~F}$-fluorodeprenyl (16), $6-{ }^{18}$ F-fluoro- $N$-methyl- $N$-(prop-2-yn-1-yl)-hexan-1-amine (17), ${ }^{18} \mathrm{~F}-\mathrm{Ro}$ 43-0463 (18), and ${ }^{18} \mathrm{~F}-(S)-3-(6-(3-$ fluoropropoxy)benzo[d] isoxazol-3-yl)-5-(methoxymethyl)-oxazolidin-2-one (19). Among those, only ${ }^{11} \mathrm{C}$-labeled compounds such as ${ }^{11} \mathrm{C}$-deprenyl $(12),{ }^{11} \mathrm{C}-\mathrm{L}-$ deprenyl- $\mathrm{D}_{2},(20)$ and ${ }^{11} \mathrm{C}-\mathrm{SL} 25.1188$ (21) were demonstrated as useful tracers for assessing MAO-B in the human brain. The short half-life of ${ }^{11} \mathrm{C}$ (20.4 min) makes these tracers less suitable for distribution to PET centers not equipped with an on-site cyclotron. So far, no successful ${ }^{18}$ F-labeled PET radioligand has been validated for clinical use. Therefore, there is keen interest in the development of an ${ }^{18} \mathrm{~F}$-labeled MAO-B inhibitor with a longer half-life and a less reversible kinetic behavior as a molecular imaging biomarker for the detection of MAO-B activity in the brain. Such a radioligand might be a useful imaging tool for the detection of activated astrocytes in central nervous system disorders such as Alzheimer disease, Parkinson disease, and epilepsy. In our recent publications, we have reported several ${ }^{18} \mathrm{~F}$-labeled radiotracers such as ${ }^{18} \mathrm{~F}$-fluorodeprenyl( $N$-[(2S)-1-1 ${ }^{18}$ F-fluoro-3-phenylpropan-2-yl]- $N$-methylprop-2-yn-1-amine) $(22,23),{ }^{18} \mathrm{~F}$-fluororasagiline $(24),(S)-N-\left(1-{ }^{18} \mathrm{~F}\right.$-fluoro-3-(furan-2-yl) propan-2-yl)- $N$-methylprop-2-yn-1-amine (25), (S)-1- ${ }^{18}$ F-fluoro- $N, 4-$ dimethyl- $N$-(prop-2-ynyl)pentan-2-amine (25), and ${ }^{18} \mathrm{~F}$-fluororasagiline$\mathrm{D}_{2}(26)$.

The present work is the continuation of our previous study in which we reported the in vivo evaluation of MAO-B in the cynomolgus 


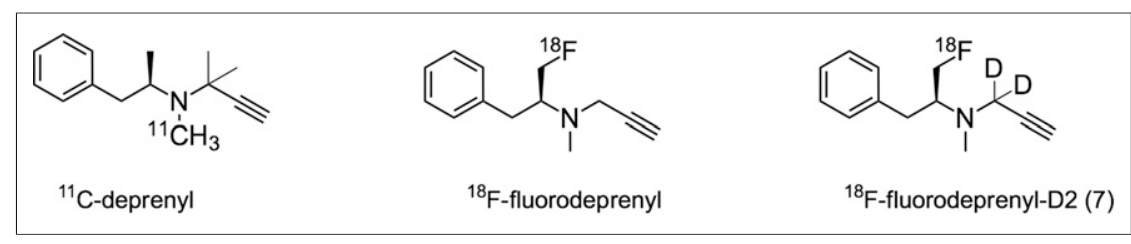

FIGURE 1. Structures of ${ }^{11} \mathrm{C}$-deprenyl, ${ }^{18} \mathrm{~F}$-fluorodeprenyl, and ${ }^{18} \mathrm{~F}$-fluorodeprenyl- $\mathrm{D}_{2}(\mathbf{7})$.

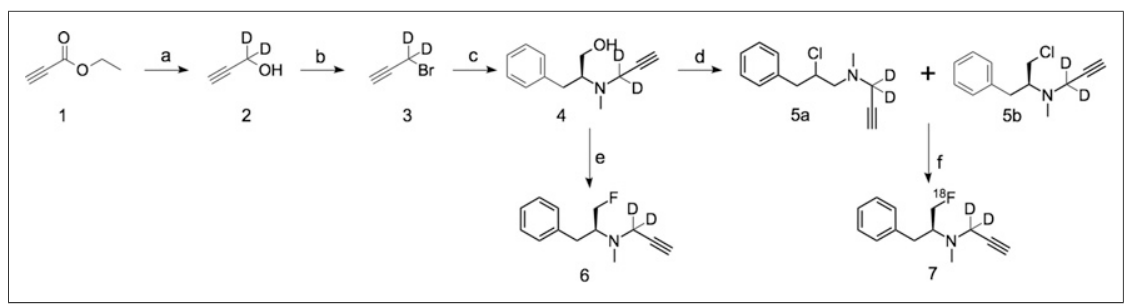

FIGURE 2. Synthesis of precursor $(\mathbf{5 a}+\mathbf{5 b})$, synthesis of reference standard $(\mathbf{6})$, and radiolabeling of ${ }^{18} \mathrm{~F}$-fluorodeprenyl- $\mathrm{D}_{2}$, (7). Conditions: a, LAD; b, $\mathrm{PBr}_{3} ; \mathrm{c}, \mathrm{K}_{2} \mathrm{CO}_{3} /\left(1,1-{ }^{2} \mathrm{H}_{2}\right)$-1-bromoprop-2-yne; $\mathrm{d}$, pyridine/mesyl chloride; e, diethylaminosulfur trifluoride; $f, K^{18} \mathrm{~F}, \mathrm{~K}-2,2,2 /$ dimethyl sulfoxide $/ \mathrm{K}_{2} \mathrm{CO}_{3}$. for $30 \mathrm{~min}$. To the stirred mixture, mesylchloride $(68.7 \mathrm{mg}, 46.4 \mu \mathrm{L}, 0.60 \mathrm{mmol})$ was added dropwise at $-7^{\circ} \mathrm{C}$, and the reaction mixture was stirred at room temperature for an additional 30 min. Saturated aqueous $\mathrm{Na}_{2} \mathrm{CO}_{3}$ solution $(1 \mathrm{~mL})$ was added and stirred for a further $30 \mathrm{~min}$. The organic layer was partitioned between $\mathrm{CH}_{2} \mathrm{Cl}_{2}(15 \mathrm{~mL})$ and water $(15 \mathrm{~mL})$. The organic phase was separated and washed with saturated $\mathrm{NaHCO}_{3}$ solution $(15 \mathrm{~mL})$ and brine $(15 \mathrm{~mL})$, dried over $\mathrm{MgSO}_{4}$, and filtered. The solvent was removed to obtain the crude product as a light yellow oil. The crude product was purified by silica-gel column chromatography $(3: 1$ hexane:ethyl acetate), and the final product (70 $\mathrm{mg}, 64 \%, 0.32 \mathrm{mmol}$ ) was obtained as a light yellow oil. The product was analyzed by nuclear magnetic resonance, highperformance liquid chromatography (HPLC), and liquid chromatography-mass spectrometry. The final product was a mixture of $\mathbf{5 a}$ (major) and $\mathbf{5 b}$ (minor). monkey brain using ${ }^{18} \mathrm{~F}$-fluorodeprenyl and also investigated its metabolism (23). Quantification of MAO-B using ${ }^{18} \mathrm{~F}$-fluorodeprenyl may not be optimal because its fast, irreversible binding to the enzyme renders the distribution of this radioligand in tissue limited by blood flow rather than by the MAO-B enzyme concentration in regions with high MAO-B activity, as was shown for ${ }^{11} \mathrm{C}$-deprenyl (20). Indeed, ${ }^{18} \mathrm{~F}$-fluorodeprenyl showed in vivo kinetic behavior similar to that of ${ }^{11} \mathrm{C}$-deprenyl (20). It has been reported that MAO-B-catalyzed cleavage of the carbon-hydrogen bond of the propargyl group at the carbon is the rate-limiting step in the retention of radioligand in the brain (27). The energy required to cleave the $\mathrm{C}-\mathrm{D}$ bond is higher than that required to cleave the $\mathrm{C}-\mathrm{H}$ bond, and the substitution of hydrogen atoms with deuterium atoms reduces the rate of cleavage. The aim of the deuteration is to decrease the affinity to MAO-B through a reduced cleavage rate of the propargyl moiety and thereby improve its sensitivity.

Therefore, our aims in this project were, first, to prepare the precursor and reference standard and develop an efficient synthetic method for labeling a novel bis-deuterium substituted L-deprenyl analog (fluorodeprenyl- $\mathrm{D}_{2}$; Fig. 1) with ${ }^{18} \mathrm{~F}$; second, to characterize its in vitro MAO-B and MAO-A inhibition based on the rate of kynuramine oxidation; third, to evaluate the in vitro autoradiography in postmortem human brain; and fourth, to study the in vivo characteristics by PET measurements in nonhuman primates (NHPs).

\section{MATERIALS AND METHODS}

\section{Chemistry}

The supplemental section details the synthesis of $\left(1,1-{ }^{2} \mathrm{H}_{2}\right)$ prop-2-yn-1-ol (2), (1,1-2 $\left.\mathrm{H}_{2}\right) 3$-bromoprop-1-yne (3), and $(S)-2-\left(\left(\left(1,1-{ }^{2} \mathrm{H}_{2}\right)-2\right.\right.$-ynyl)(methyl) amino)-3-phenyl propan-1-ol (4) (supplemental materials are available at http://jnm.snmjournals.org).

\section{Synthesis of $\mathbf{N}$-(2-Chloro-3-Phenylpropyl)- $\mathbf{N}$-Methyl-} [(1,1-2 $\left.\mathrm{H}_{2}\right)$ Prop-2-yn-1-Amine] (5a) and (S)-N-(1-Chloro-3-

Phenylpropan-2-yl)-N-Methyl-[(1,1-2 $\left.\mathbf{H}_{2}\right)$ Prop-2-yn-1-Amine] (5b)

A mixture of $4(100.0 \mathrm{mg}, 0.49 \mathrm{mmol})$ and triethyl amine $(139 \mu \mathrm{L}$, $1.0 \mathrm{mmol})$ in tetrahydrofuran $(2 \mathrm{~mL})$ was stirred at room temperature

\section{Synthesis of (S)-N-(1-Fluoro-3-Phenylpropan-2-yl)-} N-Methyl-[(1,1-2 $\left.\mathrm{H}_{2}\right)$ Prop-2-yn-1-Amine] (6)

To the stirred solution of $\mathbf{4}(100 \mathrm{mg}, 0,49 \mathrm{mmol})$ in dichloromethane $(5 \mathrm{~mL})$, diethylamino sulfur trifluoride $(132 \mu \mathrm{L}, 1.0 \mathrm{mmol})$ was added dropwise at $-5^{\circ} \mathrm{C}$, and the reaction mixture was stirred for an additional $20 \mathrm{~min}$ at the same temperature. Saturated sodium carbonate $(2.0 \mathrm{~mL})$ was added to quench unreacted diethylamino sulfur trifluoride. The organic layer was partitioned between $\mathrm{CH}_{2} \mathrm{Cl}_{2}(25 \mathrm{~mL})$ and water $(15 \mathrm{~mL})$. The organic phase was separated and washed with brine $(10 \mathrm{~mL})$ and dried over $\mathrm{MgSO}_{4}$ and filtered. The solvent was removed to obtain the crude product as a light yellow oil. The crude product was purified by silica-gel column chromatography (3:1 hexane:ether) and gave the final product (35 $\mathrm{mg}, 0.17 \mathrm{mmol}, 35 \%$ ). The product was analyzed by nuclear magnetic resonance, HPLC, and liquid chromatography-mass spectrometry.

\section{Radiosynthesis of (S)-N-(1-18 F-Fluoro-3-Phenylpropan- 2-yl)-N-Methyl-[(1,1-2 $\left.\mathrm{H}_{2}\right)$ Prop-2-yn-1-Amine] ( ${ }^{18}$ F-Fluoro- deprenyl- $\left.\mathrm{D}_{2}\right)(7)$}

${ }^{18} \mathrm{~F}$-fluoride $\left({ }^{18} \mathrm{~F}-\mathrm{F}^{-}\right)$was produced from a PETtrace cyclotron $(\mathrm{GE}$ Healthcare). A dry complex of ${ }^{18} \mathrm{~F}-\mathrm{F}^{-} / \mathrm{K}_{2} \mathrm{CO}_{3} / \mathrm{K}_{2.2 .2}$ was synthesized

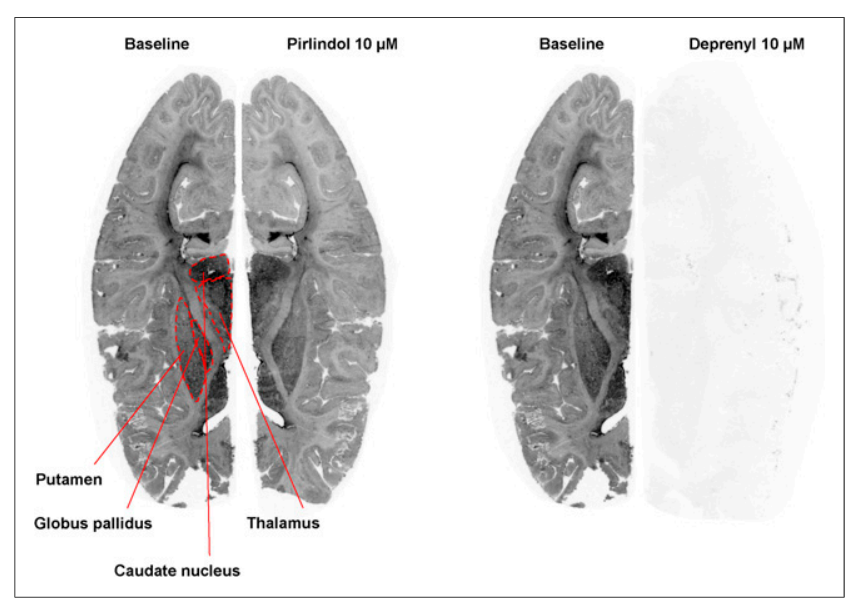

FIGURE 3. Autoradiograms of coronal slices in whole-hemisphere human brain with ${ }^{18} \mathrm{~F}$-fluorodeprenyl- $\mathrm{D}_{2}(\mathbf{7})$ at baseline condition and during incubation with pirlindole $(10 \mu \mathrm{M})$ and L-deprenyl $(10 \mu \mathrm{M})$. 


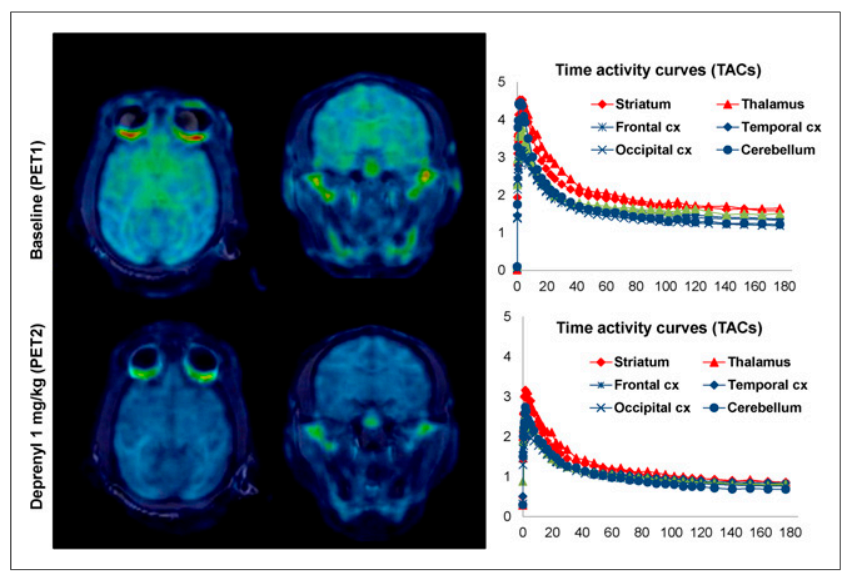

FIGURE 4. Representative fused PET/MR images of ${ }^{18} \mathrm{~F}$-fluorodeprenyl- $\mathrm{D}_{2}$ (7) and relative SUV time-activity curves under two experimental conditions (baseline and pretreatment) at level of thalamus in $1 \mathrm{NHP}$.

following a previously described method (22). The precursor $(\sim 0.02 \mathrm{mmol}$, $\sim 5 \mathrm{mg}$ ) in dimethyl sulfoxide $(500 \mu \mathrm{L})$ was added to the dry complex of ${ }^{18} \mathrm{~F}-\mathrm{F}^{-} / \mathrm{K}_{2} \mathrm{CO}_{3} / \mathrm{K}_{2.2 .2}$. The closed reaction vessel was heated at $140^{\circ} \mathrm{C}$ for $10 \mathrm{~min}$. The reaction mixture was cooled to room temperature and diluted with water to a total volume of $2 \mathrm{~mL}$ before being injected onto the HPLC column for purification. A radioactive fraction corresponding to the pure 7 (retention time, 13-14 min) was collected and diluted with water $(50 \mathrm{~mL})$. The resulting mixture was loaded onto a preconditioned SepPak tC18 Plus cartridge (Waters). The cartridge was washed with water $(10 \mathrm{~mL})$, and the isolated product was eluted with $1 \mathrm{~mL}$ of ethanol into a sterile vial containing phosphate-buffered saline solution $(9 \mathrm{~mL})$.

Determination of MAO Inhibition and In Vitro Autoradiography

Human recombinant MAO-B and MAO-A enzymes prepared from insect cells were purchased from Sigma. The assays were designed to determine the inhibition of kynuramine oxidation in the presence of the compounds of interest according to Weissbach et al. (28). The experimental procedure is detailed in the supplemental section.

Nondiseased human brains were obtained from the Department of Forensic and Insurance Medicine, Semmelweis University, Budapest. The brains had been removed during forensic autopsy (control brains) and were handled in a previously described manner (29). Ethical permission was obtained from the relevant Research Ethics Committee of the respective institutions. The experimental procedure is detailed in the supplemental section.

\section{Radiometabolite Analysis and Plasma Protein Binding}

A reversed-phase HPLC method was used to determine the percentages of radioactivity corresponding to unchanged radioligand and radiometabolites during the course of a PET measurement. The procedure is detailed in the supplemental section.

\section{Study Design Regarding NHPs, PET Experimental Procedure, and Quantification}

Three NHPs-male cynomolgus monkeys (Macaca fascicularis) were included in the study. The monkeys are owned by the Centre for Psychiatry Research, Department of Clinical Neuroscience, Karolinska Institutet. The study was approved by the Animal Research Ethical Committee of the Northern Stockholm Region Swedish Animal Welfare Agency (diarienummer N386/09 and N452/11). The experiment is detailed in the supplemental section. Altogether, 5 PET measurements of $180 \mathrm{~min}$ were performed using a high-resolution research tomograph (Siemens Molecular Imaging) on 3 macaques on separate days. Initially, a baseline measurement was performed for 3 monkeys. On separate days, two of the monkeys underwent a second PET measurement after pretreatment with the MAO-B blocker L-deprenyl $30 \mathrm{~min}$ before injection of the radioligand. L-deprenyl was infused intravenously over $10 \mathrm{~min}$, and the selected dose of $1 \mathrm{mg} / \mathrm{kg}$ was based on previous PET studies on baboons (30). T1-weighted MR images (128 images; 1.0-mm slices) were acquired on a 1.5-T Signa unit (GE Healthcare) for all monkeys. Volumes of interest were delineated on coregistered MR/PET images, and the delineation was guided by referring to an atlas obtained from 1 rhesus monkey brain. Volumes of interest for caudate, putamen, thalamus; frontal, temporal, parietal, and occipital cortex; medial temporal area; cerebellum; and whole brain were drawn using version 3.3 of PMOD (PMOD Technologies). The MR image was automatically coregistered and resliced to an average PET image using the fusion tool in PMOD. Decay-corrected time-activity curves for all regions plotted over time and radioactivity were expressed as percentage SUV.

All dynamic PET data were quantified with kinetic modeling and compartmental model analysis using the following 3 methods: 1-tissue-compartment model with 2 rate constants $\left(K_{1}, k_{2}\right)$ (1-TCM), 2-tissue-compartment model with 4 rate constants $\left(K_{1}, k_{2}, k_{3}\right.$, and $\left.k_{4}\right)(2-\mathrm{TCM} 4 \mathrm{~K})$, and 2-tissuecompartment model with 3 rate constants $\left(K_{1}, k_{2}\right.$, and $\left.k_{3}\right)(2$-TCM $3 \mathrm{~K})$. The following measures were used to directly and indirectly assess the goodness of fit: SE of residuals, the Akaike information criterion, and the Schwartz criterion. The $F$ test was used to assess whether the 2-TCM $4 \mathrm{~K}$ provided a significantly better fit than the 2 -TCM $3 \mathrm{~K}$. On the basis of this evaluation and the evident reversibility of the tracer, we selected the $2-\mathrm{TCM} 4 \mathrm{~K}$ as the model of choice and total distribution volume as

TABLE 1

Total Distribution Values $\left(\mathrm{mL} / \mathrm{cm}^{3}\right)$ Calculated with 2-TCM 4K Under Both Experimental Conditions

\begin{tabular}{|c|c|c|c|c|}
\hline \multirow[b]{2}{*}{ Region } & \multicolumn{2}{|c|}{409429 (NHP 2) } & \multicolumn{2}{|c|}{604044 (NHP 3) } \\
\hline & Baseline & Posttreatment & Baseline & Posttreatment \\
\hline Caudate & 28.69 & 10.26 & 20.97 & 11.12 \\
\hline Putamen & 24.55 & 10.29 & 18.21 & 12.28 \\
\hline Thalamus & 38.47 & 15.02 & 31.34 & 14.71 \\
\hline Frontal cortex & 22.25 & 10.15 & 21.25 & 12.60 \\
\hline Temporal cortex & 26.93 & 12.56 & 19.79 & 12.37 \\
\hline Medial temporal cortex & 34.26 & 12.42 & 20.18 & 10.87 \\
\hline Parietal cortex & 19.80 & 9.73 & 20.35 & 13.70 \\
\hline Occipital cortex & 18.63 & 8.61 & 15.52 & 13.20 \\
\hline Cerebellum & 19.10 & 6.40 & 11.04 & 8.60 \\
\hline
\end{tabular}



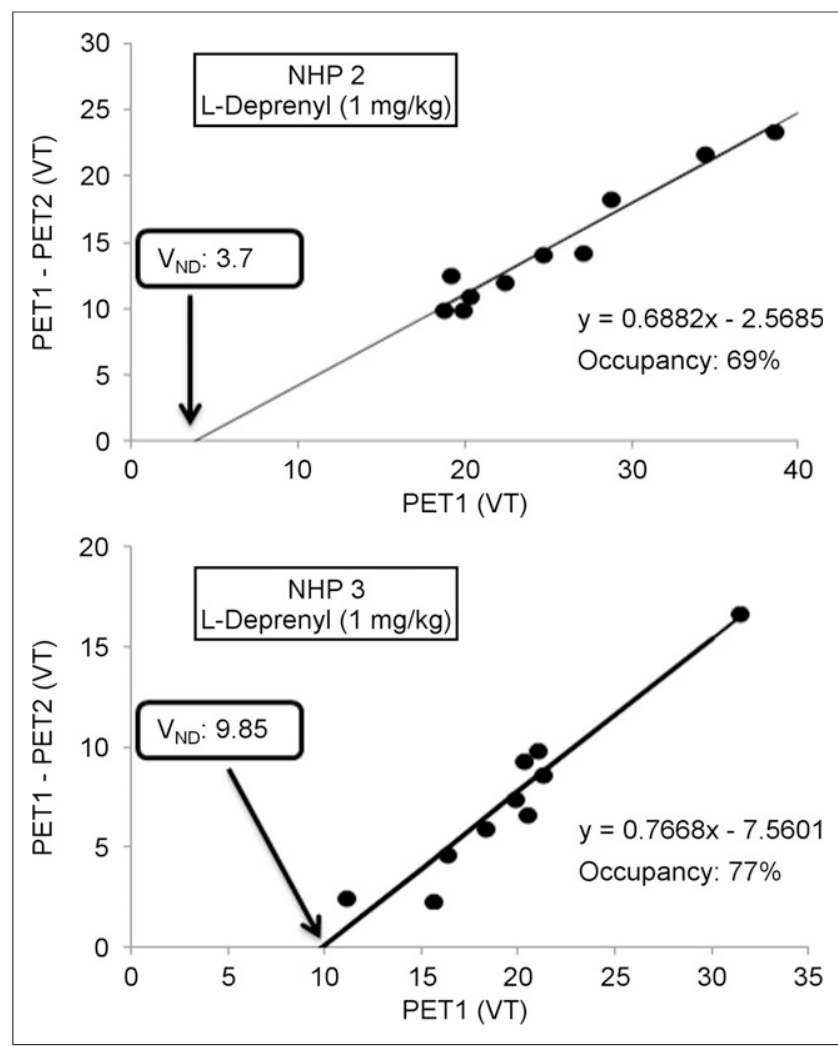

FIGURE 5. Baseline data are used along with occupancy plot to derive occupancy estimates. Data are taken from NHP 2 and NHP 3, which performed both baseline and pretreatment study with L-deprenyl, $1 \mathrm{mg} / \mathrm{kg}$. In both graphs, each data point represents regions of interest included in regression analysis. $\mathrm{V}_{\mathrm{ND}}=$ nondisplaceable volume of distribution.

the outcome measure. Accordingly, we used the revisited Lassen plot (31) to calculate the inhibition that occurred after administration of a well-known MAO-B blocker.

\section{RESULTS}

\section{Chemistry and Radiochemistry}

The precursor compounds (5a and $\mathbf{5 b}$ ) and the reference standard (6) were synthesized by standard organic synthesis from the commercially available starting material, propiolic acid (1). The radiolabeling was achieved by nucleophilic substitution of the chloroprecursor mixture of $\mathbf{5 a}$ and $\mathbf{5 b}$ by ${ }^{18} \mathrm{~F}$-fluoride in the presence of $\mathrm{K}_{2.2 .2}$ and $\mathrm{K}_{2} \mathrm{CO}_{3}$ as shown in Figure 2. The overall radiosynthesis, including the fluorination reaction, HPLC purification, solid-phase extraction purification, and radiotracer formulation, was completed within 75-80 $\mathrm{min}$. The incorporation yield of the fluorination reactions varied from $45 \%$ to $55 \%$, and the radiochemical purity was higher than $99 \%$. The identity of the labeled compound was confirmed by coinjection of the corresponding ${ }^{19} \mathrm{~F}$ analog 6 using analytic HPLC. The radioligand ${ }^{18} \mathrm{~F}$-fluorodeprenyl$\mathrm{D}_{2}$ was found to be stable in phosphate-buffered saline solution ( $\mathrm{pH}$ 7.4) for the duration of $120 \mathrm{~min} .{ }^{18} \mathrm{~F}$-fluorodeprenyl- $\mathrm{D}_{2}$ was obtained with a specific radioactivity of $677 \pm 182 \mathrm{GBq} / \mu \mathrm{mol}$.

\section{In Vitro Inhibition and Autoradiography}

Determination of MAO-B and MAO-A inhibition was based on the rate of kynuramine oxidation for the ${ }^{19} \mathrm{~F}$ analog of fluorodeprenyl- $\mathrm{D}_{2}(\mathbf{6})$ to determine its specificity for binding to MAO-B. The 50\% inhibitory concentration of compound 6 for
MAO-B was $227 \pm 36.8 \mathrm{nM}$, and that for MAO-A was more than $50 \mu \mathrm{M}$. L-deprenyl and ${ }^{18} \mathrm{~F}$-fluorodeprenyl were used as reference compounds, inhibiting MAO-B with a 50\% inhibitory concentration of $13 \pm 0.4$ and $31 \pm 2.2 \mathrm{nM}$, respectively. Thus, deuteration in compound 6 decreased the $50 \%$ inhibitory concentration toward MAO-B by about 7 times as compared with the nondeuterated fluorodeprenyl in the assay used.

The in vitro binding of ${ }^{18} \mathrm{~F}$-fluorodeprenyl- $\mathrm{D}_{2}$ was determined at the coronal and horizontal levels of whole-hemisphere human brain sections obtained from deceased subjects with no sign of any brain disorders. The ${ }^{18} \mathrm{~F}$-fluorodeprenyl- $\mathrm{D}_{2}$ radioligand showed higher selectivity for the MAO-B enzyme than for the MAO-A enzyme, as in vitro binding was almost $100 \%$ blocked with the cold ligand L-deprenyl $(10 \mu \mathrm{M})$, a selective inhibitor of the MAO-B enzyme (Fig. 3). In contrast, ${ }^{18}$ F-fluorodeprenyl- $\mathrm{D}_{2}$ binding was blocked $12 \%-20 \%$ using the cold compound pirlindole $(10 \mu \mathrm{M})$, a selective inhibitor of the MAO-A enzyme (Fig. 3). In addition, in vitro baseline binding of ${ }^{18} \mathrm{~F}$-fluorodeprenyl- $\mathrm{D}_{2}$ in whole-hemisphere human brain sections was high in the caudatus, putamen, globus pallidum, and thalamus (brain regions with high MAO-B activity), and lower radioactivity was measured in the cortex and cerebellum.

\section{PET Measurements in Cynomolgus Monkey}

The time-activity curves of ${ }^{18} \mathrm{~F}$-fluorodeprenyl- $\mathrm{D}_{2}$ uptake in a cynomolgus monkey brain are shown in Figure $4 .{ }^{18} \mathrm{~F}$-fluorodeprenyl- $\mathrm{D}_{2}$ crossed the blood-brain barrier and bound rapidly, with an average time

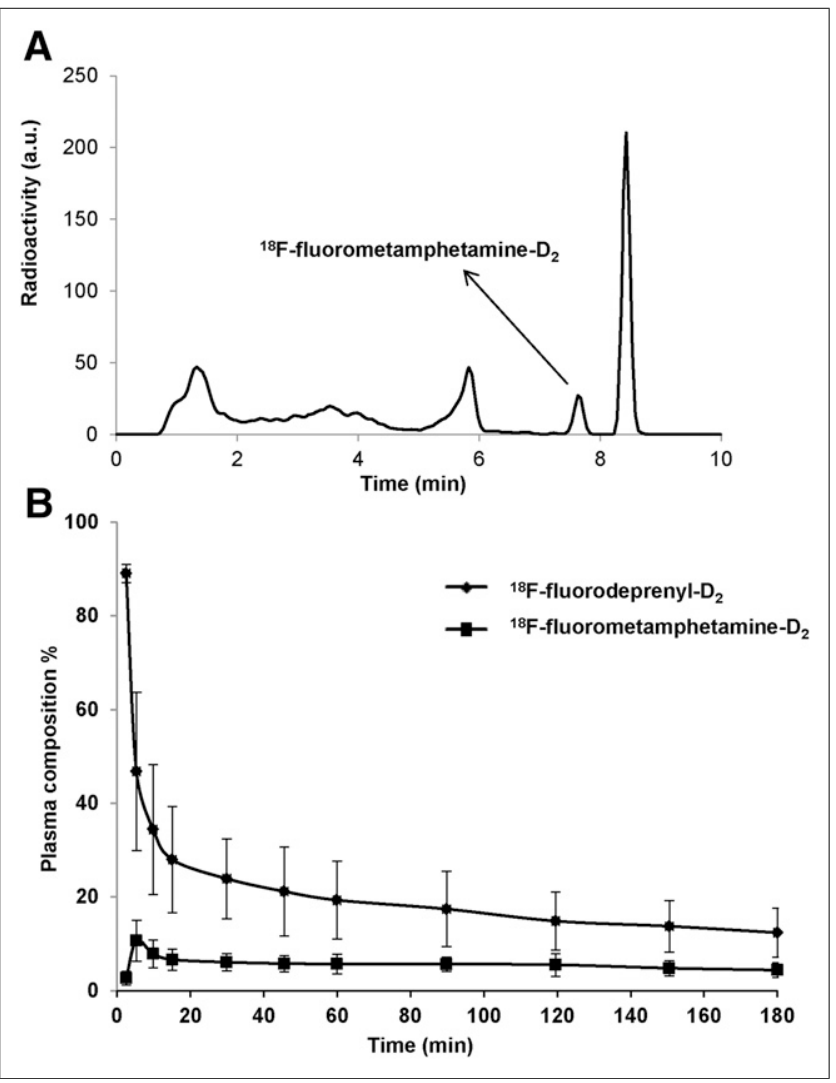

FIGURE 6. (A) Radiochromatogram of plasma taken 30 min after injection of radioligand. (B) In vivo metabolism of ${ }^{18} \mathrm{~F}$-fluorodeprenyl- $\mathrm{D}_{2}(\mathbf{7})$ shown as relative plasma composition of parent compound and identified radiometabolite ${ }^{18} \mathrm{~F}$-flurometamphatamine- $\mathrm{D}_{2}$ in total plasma radioactivity during $180 \mathrm{~min}$ of PET scan. Values are average of measurements performed on 3 cynomolgus monkeys. a.u. = arbitrary unit. 


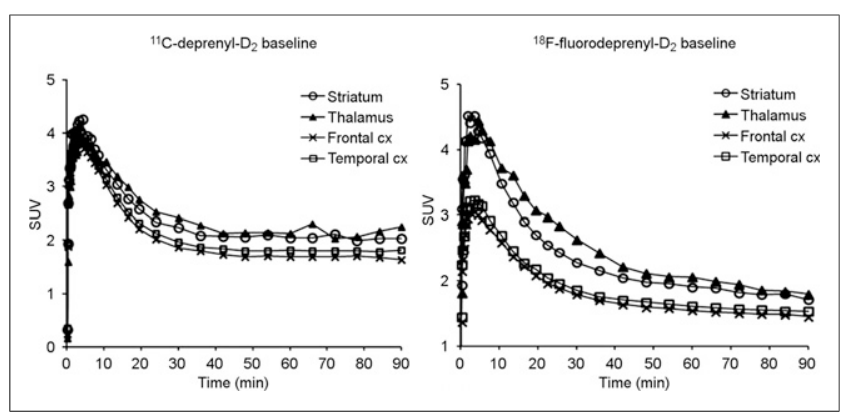

FIGURE 7. Head-to-head comparison of two baseline scans performed under same experimental condition on the same NHP (NHP 3) with ${ }^{11} \mathrm{C}$-deprenyl- $\mathrm{D}_{2}(\mathrm{~A})$ and ${ }^{18} \mathrm{~F}$-fluorodeprenyl- $\mathrm{D}_{2}$ (B). $\mathrm{cx}=$ cortex.

to peak of $4 \mathrm{~min}$. At baselines, the highest radioactivity concentrations (expressed as SUV) were in the striatum $(5.1 \pm 1.6)$ and thalamus $(4.6 \pm 1.3)$, followed by the medial temporal area $(4.6 \pm 2.5)$. Overall, ${ }^{18} \mathrm{~F}$-fluorodeprenyl- $\mathrm{D}_{2}$ showed fast and constant washout from the brain in subcortical and cortical regions on baseline scans (Fig. 4). The 1-TCM did not provide a good fitting by visual inspection, suggesting the presence of a kinetically distinguished compartment, and was not pursued for further analysis. The 2-TCM $4 \mathrm{~K}$ estimated the parameters in all baseline scans significantly better than the 2-TCM $3 \mathrm{~K}$ except for the thalamus of a single NHP. Administration of L-deprenyl $(1.0 \mathrm{mg} / \mathrm{kg})$ decreased ${ }^{18} \mathrm{~F}$-fluorodeprenyl- $\mathrm{D}_{2}$ binding in all brain regions and determined a clear change in the slope of the time-activity curves (Fig. 4). The 2-TCM $4 \mathrm{~K}$ provided, in the pretreatment condition, a statistically significant improvement in fitting of the data in a single NHP. Overall, 4 of 5 experiments did show a better estimation of the parameters with the $2-\mathrm{TCM} 4 \mathrm{~K}$, providing total distribution volume estimates that could be used as an outcome measure (Table 1). Thereby, MAO-B occupancy of L-deprenyl calculated with the revised Lassen plot was 69\% (NHP 2) and 77\% (NHP 3). Nondisplaceable volumes of distribution estimated at the $x$-axis intercept in the Lassen plots were 3.7 and $9.8 \mathrm{~mL} / \mathrm{cm}^{3}$, respectively (Fig. 5).

\section{Radiometabolite Analysis}

The radioactivity in arterial blood samples, plasma, and the remaining protein pellet after deproteinization of plasma with acetonitrile was measured by a well counter. Recovery of radioactivity from plasma into acetonitrile was more than $85 \%$. The plasma obtained from arterial blood samples taken at various time points after the injection of ${ }^{18} \mathrm{~F}$ fluorodeprenyl- $\mathrm{D}_{2}$ was analyzed by radio-HPLC. All detected radiometabolites were less lipophilic than the radioligand. The most lipophilic radiometabolite, eluting with a retention time of $7.9 \mathrm{~min}$ closely before the radioligand retention time, $8.6 \mathrm{~min}$, was identified as ${ }^{18} \mathrm{~F}$-fluorometamphatamine- $\mathrm{D}_{2}$ (Fig. 6A) by comparing its retention time with that of the synthesized reference compound. Approximately $5 \%$ of the total radioactivity originated from ${ }^{18} \mathrm{~F}$-fluorometamphetamine$\mathrm{D}_{2}$ during the PET scan, as shown in Figure 6B.

Protein binding of ${ }^{18} \mathrm{~F}$-fluorodeprenyl- $\mathrm{D}_{2}$ was measured using ultrafiltration, and an average of $33.8 \% \pm 4.1 \%$ of the radioligand was in protein-free form.

\section{DISCUSSION}

It has been shown that the dideuterated derivative of the MAO-B inhibitor deprenyl can be used as a marker for the density of astrocytes in the brain $(32,33)$. In the present study we show the potential of ${ }^{18} \mathrm{~F}$ fluorodeprenyl- $\mathrm{D}_{2}$ to visualize MAO-B activity in vivo.
Compound 2 was synthesized by treating propiolic acid with lithium aluminum deuteride. The key parameter of this reaction was to keep the temperature below $-50^{\circ} \mathrm{C}$. In the second step, 2 was brominated with $\mathrm{PBr}_{3}$ to synthesize 3. Compound 4 was synthesized from 3 and (4R,5R)-4-methyl-5-phenyl-3-(prop-2-ynyl)oxazolidin-2one following a previously described procedure (22). A mixture of two chlorinated isomers, $\mathbf{5 a}$ and $\mathbf{5 b}$, was formed from $\mathbf{4}$ on treatment with mesylchloride. Fluoride $\mathbf{6}$ was also synthesized from amino alcohol 4 by fluorination with diethylamino sulfur trifluoride. The formation of regioisomeric chlorides $\mathbf{5 a}$ and $\mathbf{5 b}$ can be explained by an intermediate aziridinium ion resulting from an intramolecular nucleophilic substitution attack of the free electron pair of the nitrogen, as has been previously described elsewhere (34). Radiolabeling was done by a 1-step nucleophilic substitution reaction in which chloride was substituted by ${ }^{18} \mathrm{~F}$-fluoride. The synthesis resulted in two isomers of ${ }^{18} \mathrm{~F}$-labeled products, which were purified by a semipreparative HPLC column.

High in vitro ${ }^{18} \mathrm{~F}$-fluorodeprenyl- $\mathrm{D}_{2}$ binding was measured in several brain regions with high MAO-B activity, and L-deprenyl $(10 \mu \mathrm{M})$ successfully displaced all ${ }^{18} \mathrm{~F}$-fluorodeprenyl- $\mathrm{D}_{2}$ binding. In NHPs in vivo, ${ }^{18} \mathrm{~F}$-fluorodeprenyl- $\mathrm{D}_{2}$ showed favorable kinetic properties, with relatively steady washout from the brain in most experiments and conditions. The deuteration seemed, in vivo, to lead to a further reduction in covalent binding of the tracer to the enzyme, resulting in a less irreversible behavior even when it was compared, in the same experimental condition and NHP, with the ${ }^{11} \mathrm{C}$-deprenyl- $\mathrm{D}_{2}$ kinetic (Fig. 7 and supplemental section). In the present study, a more reversible kinetic of ${ }^{18} \mathrm{~F}$-fluorodeprenyl- $\mathrm{D}_{2}$ was confirmed by model comparison. The 2-TCM suitable for irreversible tracers (2-TCM $3 \mathrm{~K}$ ) did not perform best in terms of fitting in most experiments; hence, the 2-TCM $4 \mathrm{~K}$ was the most appropriate model to describe the brain kinetic of ${ }^{18} \mathrm{~F}$-fluorodeprenyl- $\mathrm{D}_{2}$. Consequently, estimation of total distribution volume was considered a more reliable outcome measure to evaluate the availability of MAO-B in NHPs. Moreover, estimates of nondisplaceable volume of distribution obtained from the revised Lassen plot allowed for measurement of the level of specific binding, which in the case of a high-density MAO-B region such as the thalamus (total distribution volumes of $34.91 \mathrm{~mL} / \mathrm{cm}^{3}$ on average) was quite high $(79 \%$ on average). The calculated occupancy after pretreatment with deprenyl $(1 \mathrm{mg} / \mathrm{kg})$ was higher (77\% vs. $61.7 \%$ ) than a previous estimation obtained with ${ }^{11} \mathrm{C}$-deprenyl-D $\mathrm{D}_{2}$ (Supplemental Table 3).

It has been reported that the two main radiometabolites of ${ }^{11} \mathrm{C}$ deprenyl are ${ }^{11} \mathrm{C}-\mathrm{CO}_{2}$ and ${ }^{11} \mathrm{C}$-metamphetamine (35) and that at 30 min after injection, $30 \%$ of the total radiometabolites found in baboon plasma is in the form of ${ }^{11} \mathrm{C}-\mathrm{CO}_{2}$. In the case of ${ }^{18} \mathrm{~F}$ fluorodeprenyl- $\mathrm{D}_{2}$, there is no possibility of having radiolabeled $\mathrm{CO}_{2} ;{ }^{18} \mathrm{~F}$-fluorometamphetamine- $\mathrm{D}_{2}$ is more likely. The potential specific contribution of one of the most lipophilic radiometabolites is questionable. Indeed, one of the identified radiometabolites, ${ }^{18} \mathrm{~F}$ fluorometamphetamine- $\mathrm{D}_{2}$, was observed at less than $5 \%$ on average and in some NHPs was not separated on the HPLC because of its low amount. A structurally similar radiotracer has been shown to enter the human brain and bind primarily to monoamine transporters (36).

The presence of such an amount of ${ }^{18} \mathrm{~F}$-fluorometamphetamine$\mathrm{D}_{2}$ in the plasma might contribute to a small increase in nonspecific binding of ${ }^{18} \mathrm{~F}$-fluorodeprenyl- $\mathrm{D}_{2}$ in the brain. Future challenges would include optimization of the HPLC conditions to achieve a better separation of radiometabolites in plasma and to investigate blood-brain barrier-penetrating radiometabolites using mouse models. 


\section{CONCLUSION}

In the present work, an efficient synthesis strategy for an ${ }^{18} \mathrm{~F}$ labeled deuterium substituted fluoro-analog of L-deprenyl was established, yielding the target compound. In vitro, MAO inhibition demonstrated a moderate binding affinity to recombinant MAO-B. In vitro autoradiography demonstrated selective binding to brain regions, such as the striatum, containing MAO-B. In vivo characteristics in a cynomolgus monkey showed moderate uptake in brain regions known to be rich in MAO-B. The deuterated analog of ${ }^{18} \mathrm{~F}-$ fluorodeprenyl is more stable in monkey blood plasma than the nondeuterated analog. In addition, the deuteration reduced the rate of radioligand trapping in the monkey brain, leading to improved sensitivity. The PET studies were confirmed by the kinetic analysis performed on NHPs. A faster kinetic and the fluorine labeling are possible advantages over other, previously developed, MAO-B imaging radioligands such as ${ }^{11} \mathrm{C}-\mathrm{D}_{2}$-deprenyl. Together, these results suggest that ${ }^{18} \mathrm{~F}$-fluorodeprenyl- $\mathrm{D}_{2}$ is an improved PET radioligand for visualization of MAO-B activity in the human brain.

\section{DISCLOSURE}

The costs of publication of this article were defrayed in part by the payment of page charges. Therefore, and solely to indicate this fact, this article is hereby marked "advertisement" in accordance with 18 USC section 1734. This research received funding from the European Union's Seventh Framework Programme (FP7/2007-2013) under grant agreement HEALTHF2-2011-278850 (INMiND). No other potential conflict of interest relevant to this article was reported.

\section{ACKNOWLEDGMENT}

We thank all the members of Karolinska Institutet PET Centre.

\section{REFERENCES}

1. Shih JC, Chen K, Ridd MJ. Monoamine oxidase: from genes to behavior. Annu Rev Neurosci. 1999;22:197-217.

2. Hirvonen J, Kailajarvi M, Haltia T, et al. Assessment of MAO-B occupancy in the brain with PET and $\left[{ }^{11} \mathrm{C}\right]-\mathrm{L}$-deprenyl-D2: a dose-finding study with a novel MAO-B inhibitor, EVT 301. Clin Pharmacol Ther. 2009;85:506-512.

3. Langston JW, Ballard P, Tetrud JW, Irwin I. Chronic Parkinsonism in humans due to a product of meperidine-analog synthesis. Science. 1983;219:979-980.

4. Pérez V, Marco JL, Fernandez-Alvarez E, Unzeta M. Relevance of benzyloxy group in 2-indolyl methylamines in the selective MAO-B inhibition. Br J Pharmacol. 1999;127:869-876.

5. Bach AWJ, Lan NC, Bruke DJ, et al. Molecular-cloning of human monoamine oxidase-A and oxidase-B (MAO-A and MAO-B). FASEB J. 1988;2:A1733-A1733.

6. Cesura AM, Pletscher A. The new generation of monoamine oxidase inhibitors. Prog Drug Res. 1992;38:171-297.

7. Tipton KF, Boyce S, O'Sullivan J, Davey GP, Healy J. Monoamine oxidases: certainties and uncertainties. Curr Med Chem. 2004;11:1965-1982.

8. Smith MA, Rottkamp CA, Nunomura A, Raina AK, Perry G. Oxidative stress in Alzheimer's disease. Biochim Biophys Acta. 2000;1502:139-144.

9. Gulyás B, Pavlova E, Kasa P, et al. Activated MAO-B in the brain of Alzheimer patients, demonstrated by [C-11]-L-deprenyl using whole hemisphere autoradiography. Neurochem Int. 2011;58:60-68.

10. Carter SF, Scholl M, Almkvist O, et al. Evidence for astrocytosis in prodromal Alzheimer disease provided by $\left[{ }^{11} \mathrm{C}\right]$-deuterium-L-deprenyl: a multitracer PET paradigm combining $\left[{ }^{11} \mathrm{C}\right]$-Pittsburgh compound B and ${ }^{18}$ F-FDG. J Nucl Med. 2012;53:37-46.

11. Nordberg A. Molecular imaging in Alzheimer's disease: new perspectives on biomarkers for early diagnosis and drug development. Alzheimers Res Ther. 2011;3:34.

12. Fowler JS, Macgregor RR, Wolf AP, et al. Mapping human-brain monoamine oxidase-A and oxidase-B with C-11 labeled suicide inactivators and PET. Science. $1987 ; 235: 481-485$.
13. Ishiwata $\mathrm{K}$, Ido $\mathrm{T}$, Yanai $\mathrm{K}$, et al. Biodistribution of a positron-emitting suicide inactivator of monoamine oxidase, carbon-11 pargyline, in mice and a rabbit. $J$ Nucl Med. 1985;26:630-636.

14. Saba W, Valette H, Peyronneau MA, et al. $\left[{ }^{11} \mathrm{C}\right] \mathrm{SL} 25.1188$, a new reversible radioligand to study the monoamine oxidase type B with PET: preclinical characterisation in nonhuman primate. Synapse. 2010;64:61-69.

15. Hirata M, Kagawa S, Yoshimoto M, Ohmomo Y. Synthesis and characterization of radioiodinated MD-230254: a new ligand for potential imaging of monoamine oxidase B activity by single photon emission computed tomography. Chem Pharm Bull (Tokyo). 2002;50:609-614.

16. Plenevaux A, Fowler JS, Dewey SL, Wolf AP, Guillaume M. The synthesis of nocarrier-added DL-4- $\left[{ }^{18} \mathrm{~F}\right]$ fluorodeprenyl via the nucleophilic aromatic substitution reaction. Int J Rad Appl Instrum [A]. 1991;42:121-127.

17. Mukherjee J, Yang ZY, Lew R. N-(6- ${ }^{18}$ F-fluorohexyl)-N-methylpropargylamine: a fluorine-18-labeled monoamine oxidase B inhibitor for potential use in PET studies. Nucl Med Biol. 1999;26:111-116.

18. Bläuenstein P, Remy N, Buck A, Ametamey S, Haberli M, Schubiger PA. In vivo properties of $\mathrm{N}$-(2-aminoethyl)-5-halogeno-2-pyridinecarboxamide ${ }^{18} \mathrm{~F}$ - and ${ }^{123}$ I-labelled reversible inhibitors of monoamine oxidase B. Nucl Med Biol. 1998;25:47-52.

19. Hicks JW, Sadovski O, Parkes J, et al. Radiosynthesis and ex vivo evaluation of [F-18](S)-3-(6-(3-fluoropropoxy)benzo[d]isoxazol-3-yl)-5-(methoxymethyl)oxazolidin-2one for imaging MAO-B with PET. Bioorg Med Chem Lett. 2015;25:288-291.

20. Fowler JS, Wang GJ, Logan J, et al. Selective reduction of radiotracer trapping by deuterium substitution: comparison of carbon-11-L-deprenyl and carbon-11deprenyl-D2 for MAO B mapping. J Nucl Med. 1995;36:1255-1262.

21. Rusjan PM, Wilson AA, Miler L, et al. Kinetic modeling of the monoamine oxidase B radioligand $\left[{ }^{11} \mathrm{C}\right] \mathrm{SL} 25.1188$ in human brain with high-resolution positron emission tomography. J Cereb Blood Flow Metab. 2014;34:883-889.

22. Nag S, Lehmann L, Heinrich T, et al. Synthesis of three novel fluorine-18 labeled analogues of L-deprenyl for positron emission tomography (PET) studies of monoamine oxidase B (MAO-B). J Med Chem. 2011;54:7023-7029.

23. Nag $\mathrm{S}$, Varrone $\mathrm{A}$, Toth $\mathrm{M}$, et al. In vivo evaluation in cynomolgus monkey brain and metabolism of $\left[{ }^{18} \mathrm{~F}\right]$ fluorodeprenyl: a new MAO-B pet radioligand. Synapse. 2012;66:323-330.

24. Nag S, Lehmann L, Kettschau G, et al. Synthesis and evaluation of F-18 fluororasagiline, a novel positron emission tomography (PET) radioligand for monoamine oxidase B (MAO-B). Bioorg Med Chem. 2012;20:3065-3071.

25. Nag S, Kettschau G, Heinrich T, et al. Synthesis and biological evaluation of novel propargyl amines as potential fluorine-18 labeled radioligands for detection of MAO-B activity. Bioorg Med Chem. 2013;21:186-195.

26. Nag S, Lehmann L, Kettschau G, et al. Development of a novel fluorine-18 labeled deuterated fluororasagiline ([F-18]fluororasagiline-D-2) radioligand for PET studies of monoamino oxidase B (MAO-B). Bioorg Med Chem. 2013;21:6634-6641.

27. Fowler JS, Wolf AP, MacGregor RR, et al. Mechanistic positron emission tomography studies: demonstration of a deuterium isotope effect in the monoamine oxidase-catalyzed binding of $\left[{ }^{11} \mathrm{C}\right] \mathrm{L}$-deprenyl in living baboon brain. J Neurochem. 1988;51:1524-1534.

28. Weissbach H, Smith TE, Daly JW, Witkop B, Udenfriend S. A rapid spectrophotometric assay of mono-amine oxidase based on the rate of disappearance of kynuramine. J Biol Chem. 1960;235:1160-1163.

29. Hall H, Halldin C, Farde L, Sedvall G. Whole hemisphere autoradiography of the postmortem human brain. Nucl Med Biol. 1998;25:715-719.

30. Arnett CD, Fowler JS, MacGregor RR, et al. Turnover of brain monoamine oxidase measured in vivo by positron emission tomography using L-[ $\left.{ }^{11} \mathrm{C}\right] \mathrm{dep}-$ renyl. J Neurochem. 1987;49:522-527.

31. Cunningham VJ, Rabiner EA, Slifstein M, Laruelle M, Gunn RN. Measuring drug occupancy in the absence of a reference region: the Lassen plot re-visited. $J$ Cereb Blood Flow Metab. 2010;30:46-50.

32. Bergström M, Kumlien E, Lilja A, Tyrefors N, Westerberg G, Langstrom B. Temporal lobe epilepsy visualized with PET with C-11-L-deuterium-deprenyl: analysis of kinetic data. Acta Neurol Scand. 1998;98:224-231.

33. Fowler JS, Logan J, Wang GJ, et al. Comparison of the binding of the irreversible monoamine oxidase tracers, $\left[{ }^{11} \mathrm{C}\right]$ clorgyline and $\left[{ }^{11} \mathrm{C}\right] \mathrm{L}$-deprenyl in brain and peripheral organs in humans. Nucl Med Biol. 2004;31:313-319.

34. Métro TX, Appenzeller J, Pardo DG, Cossy J. Highly enantioselective synthesis of beta-amino alcohols. Org Lett. 2006;8:3509-3512.

35. Yoshida T, Yamada Y, Yamamoto T, Kuroiwa Y. Metabolism of deprenyl, a selective monoamine oxidase (MAO) B inhibitor in rat: relationship of metabolism to MAO-B inhibitory potency. Xenobiotica. 1986;16:129-136.

36. Fowler JS, Volkow ND, Logan J, et al. Fast uptake and long-lasting binding of methamphetamine in the human brain: comparison with cocaine. Neuroimage. 2008;43:756-763. 